\title{
Temporal Trajectories of HR/VHR Pixels and Detection of Land Take Processes
}

\author{
C. Iannucci
}

IPTSAT, Rome, Italy

\begin{abstract}
An increasing share of people and economic activities are attracted by the cities. This fact shows positive aspects and at the same time causes challenges, mainly in reference to the soil whose ecosystem services can be disrupted when the land cover is modified. Therefore, urbanization is a critical issue for the land management.

Contrasting the urban sprawl (i.e. the spontaneous, unplanned process transforming vegetated land covers into artificial ones) is relevant for soil protection in terms of minimizing the land take. Remote sensing technologies have provided support (with an ex-post approach) to understand urban sprawl as a process and to assess its impacts on the sustainability of land management. The current availability of high-resolution/ very-high-resolution (HR/VHR) satellite data suggests to explore a different approach, aiming to deploy timely adequate countermeasures.

The analysis of the urban sprawl processes pinpoints how the induced land cover changes show some specific patterns; moreover, distinctive trajectories in the space of multitemporal / multispectral imagery data can be elicited, relying also upon vegetation indices as the Normalized Difference Vegetation Index (NDVI). Accordingly, suitable precursors of urban sprawl processes can be detected. Such precursors can support a novel ex-ante approach in preventing the consolidation of the outcomes of the urban sprawl processes.
\end{abstract}

\section{Keywords}

Sustainable land management, urbanization, land cover change, remote sensing, satellite imagery, spatio-temporal trajectories, urban sprawl.

Iannucci, C. (2016) "Temporal Trajectories of HR/VHR Pixels and Detection of Land Take Processes", AGRIS on-line Papers in Economics and Informatics, Vol. 8, No. 1, pp. 37 - 44. ISSN 1804-1930. DOI: 10.7160/aol.2016.080104.

\section{Introduction}

Urbanization expands as a response both to the increasing population (requesting new dwellings) and to modifications of the life styles (lowering the quantity of inhabitants per single house and enlarging the built surface available per single inhabitant). It has been estimated that the urbanized population in Europe and in northern America will reach an amount in the range $78 \%$ to $85 \%$ of the total by 2030 (UNDESA, 2012).

It can be shown that economic development and enlargement of the urban areas are positively correlated. Moreover, compact, densely populated cities can match an increase in economic productivity to a lower consume of resources per person, when a conscious urban governance (specifically, in terms of land planning) is available
(EEA, 2015). From this point of view, urbanization is a positive process.

On the other hand, it has to be taken into account that the global footprint of a urban area is usually greater than the area delimited by the city own borders. The above mentioned urbanization trend implies challenging stresses on the interested communities. Accordingly, new problems at unprecedented quantitative and qualitative scales have to be dealt with, in order not to overcome the social and ecological resilience of the interested areas. Among those problems, the soil consumption (i.e. the transformation of the land cover from agriculture and nature to other artificialized classes) appears to be of utter concern; its management requires novel approaches and tools. 


\section{Materials and methods}

The concepts of land cover, land use and land take are presented, in order to establish a basis for the subsequent analysis. Land take is related to soil sealing and to urban sprawl, both of them disrupting the ecoservices provided by the soil, as a consequence of mostly unplanned changes. An improved land management is necessary in order to control the changes induced by land take. To such purpose, data provided by satellites can be effectively exploited, relying on the increased resolutions of the currently available sensors.

\section{Some definitions}

A basic definition of land cover is «the vegetational and artificial constructions covering the land surface» (Anderson et al., 1976). INSPIRE (the EU initiative establishing a spatial data infrastructure in Europe) provides an operational definition of land cover as «physical and biological cover of the earth's surface including artificial surfaces, agricultural areas, forests, (semi-)natural areas, wetlands, water bodies.» (INSPIRE, 2007); it also suggests a more generic one in terms of «an abstraction of the physical and biophysical cover on the earth's surface» (INSPIRE LC, 2013).

Land use (even if often intertwined with land cover) is a description of the «territory characterized according to its current and future planned functional dimension or socio-economic purpose (e.g. residential, industrial, commercial, agricultural, forestry, recreational)» (INSPIRE, 2007). An earlier and more compact definition is reported by (Anderson et al., 1976), in terms of «man's activities on land which are directly related to the land».

In Europe, a good level of land cover data harmonization has been provided by the EEA CORINE Land Cover program and the Eurostat LUCAS survey; for both the existing and planned land use, INSPIRE has produced the Hierarchical INSPIRE Land Use Classification System (HILUCS). Strictly speaking, each member State can still use its own classification system; the INSPIRE Directive requires data interoperability, not necessarily data harmonization (at least, as far as suitable transformation tools are made available).

Dealing with the concept of soil consumption (globally referred to as land take), the European Environment Agency (EEA) has analyzed the mutual relations of land take to soil sealing and urban sprawl (Turner, 2002). Soil sealing refers to the generic processes that are responsible of the covering of soil (both urban and agricultural) by impermeable materials (as those used in the building industry or by agricultural practices) in a way that disrupts the ecosystem services expected from the soil as itself. When such disruption of ecosystem services is practically irreversible (as in most cases), land take increases and, at the same time, portions of territory show different land cover.

Such cover changes occur as a consequence of both planned (i.e. duly authorized) and spontaneous (i.e. not legally foreseen) initiatives of development of non-artificialized land. In the latter case, the cover change is usually the result of the urban sprawl, defined as «the physical pattern of low-density expansion of large urban areas, under market conditions, mainly into the surrounding agricultural areas... [it is] synonymous with unplanned incremental urban development, characterized by a low density mix of land uses on the urban fringe» (EEA, 2006). It is worth noting that the above mentioned definition of the urban sprawl includes a subset only of the more general phenomena of the artificialization of the fringes of the urban areas, phenomena that can have an heavy impact on the environment even if they have duly been authorized.

However, it appears that not everybody dealing with the European environment is acting on the basis of the EEA definition, e.g. the INSPIRE data specifications include the Annex B (even if labeled as "informative", not "normative") where the sprawl is seen as a physiological, not pathological, aspect of the urbanization: «Urban sprawl is an intrinsic dimension of urbanization, which underlies the processes of spatial diffusion occurring in most developed countries. It has been shown that urban sprawl can increase the aggregate urban land use and lower the average land use density while at the same time lowering average commuting travel times and increasing discretionary mobility...Urban sprawl is considered acceptable when the rate of urban sprawling is similar to the population increase» (INSPIRE LU, 2013).

It is interesting to compare and contrast the last sentence of the paragraph above with the fact that the expansion rates of the residential urban areas and of industrial areas have been recorded since 1990 as respectively four times and seven times the rate of increase of population (EEA, 2013). Anyhow, EU policies globally see the need of reducing and mitigating the negative effects of soil sealing (whose expansion the urban sprawl is 
a major component), aiming to achieve no net land take by 2050 through the diffusion of applicable best practices and the improvement of relevant governance processes (EC, 2011).

In such context, an improved land management (specifically in terms of halting the urban sprawl) can effectively contribute to minimize the land take and to establish a more sustainable equilibrium among the various land uses. Satellite data can be useful when exploited in the frame of a suitable methodology, supporting their fusion with data from other relevant sources and allowing to detect the urban sprawl since its earliest appearance.

\section{Remote sensing and urban sprawl}

Remote sensing (RS) technology has been widely exploited to survey the land (including the urban areas) and to monitor its changes, since the launch of the Landsat-2 satellite in 1975. Urban sprawl effects have became a subject of interest at the beginning of the Eighties, mainly in correlation with the availability of the improved sensors onboard of satellites as Landsat-4 since 1982 and SPOT-1 since 1986. A review of concepts and applications of RS to urban studies is provided by (Bhatta, 2010). A review of the requirements for sustainable land management and of possible uses of RS is provided by (Skidmore et al., 1997).

RS capabilities for land cover assessment have been extensively investigated since the availability of the Multi-Spectral Scanner (MSS) of Landsat-2. The extension of the studies in this domain has been supported by the improved resolutions of the subsequent sensors, starting with the Thematic Mapper (TM) on Landsat since 1982; the Enhanced Thematic Mapper Plus (ETM+) on Landsat since 1999; the High Resolution Visible (HRV) on SPOT since 1986). The initial focus was on defining the actual borders and the past changes of the urban areas.

Currently, future land cover evolutions are mainly estimated as the product of mathematical modeling, possibly supported by aerial and satellite imagery processed by geographical information system (GIS) tools and providing data to simulation models. RS data are mostly used to analyze the actual state of the land cover, in reference to the previous states. i.e. with a ex-post approach: this applies specifically to the description of the urban sprawl phenomena (as in (Ji et al., 2006)).

Earlier sensors (MSS, TM, ETM+ ...) from one hand were adequate for such approach. On the other hand, sensors with largely improved resolutions (i.e. up to few meters spatially; return time of few days; more spectral bands) are currently available on recent satellites (e.g. Ikonos-2, QuickBird, RapidEye, Landsat-8, Sentinel-2); the related data suggest to investigate about the feasibility of an ex-ante approach, on the basis of a novel methodology aiming to detect the urban sprawl before its consolidation. Taking into account the actual level of urbanization in Europe, proactive land protection appears to be more effective (even if more demanding) than reactive sanctions of unplanned transformations.

From the very beginning, data interpretation has exploited various algorithms (supervised or unsupervised clustering, linear regression estimators etc.) to categorize groups of spectrally homogeneous pixels, aiming to associate such groups with actual land cover classes. Principal components analysis (PCA) has proved its efficacy in filtering redundant data. Trying to improve the results provided by such "per-pixel" methods, the image interpretation processes have been extended in order to include:

- The time information, by jointly processing images taken in different dates for the same areas;

- The spatial information, carried mainly by image texture and pixel proximity.

The current Object-Based Image Classification (OBIA) methods rely specifically on the latter approach. Such methods, reviewed by [Blaschke, 2010], provide new paradigms for image classification and are specifically suitable for HR/ VHR (High Resolution/Very High Resolution) image analysis.

The inclusion of the time information, in particular, has supported the definition of temporal trajectories of the land covers. The spectral properties of the pixels show evolutions that can be revealed by suitable data transformations. For agricultural and natural areas, such evolutions can be foreseen on the basis of information provided by phenological calendars. Being such calendars specific for each vegetal canopy, land cover classes with similar spectral signatures (e.g. wheat and pasture) can be discriminate analyzing the temporal trajectories of their pixels, whose reflectance will reach its annual maximum in different dates and usually along different paths in the spectral space (Schwartz, 2013).

Relying on such improvements, the definition 
of a RS-based methodology for the early (i.e. ex-ante) detection of urban sprawl appears to be feasible. To such purpose, it is useful to examine the processes of land cover changes in the periurban areas.

\section{Results and discussion}

The urban sprawl mostly modifies the land cover and the land use of areas previously devoted to agricultural practices. Such modification shown specific paths, whose steps can be timely detected by radiometric changes. The vegetation indices and the phenological trajectories of the areas potentially targeted by the urban sprawl support the early detection of modifications in progress, before their consolidation. This appears to be of interest, because halting the land modifications is usually more efficient that restoring the previous states.

Urban sprawl as a process

Urban sprawl is mainly related to land take in agricultural areas where cropping practices are being abandoned (usually with the aim of increasing the financial return of such areas). With reference to the EEA definition (EEA, 2006) as mentioned in the above, the urban sprawl is a consequence of individual decisions (out or against planning policies) of land artificialization, contributing to the larger process of urbanization and of related land take. Such individual decisions have an impact mostly on privately owned parcels previously exploited for the agriculture, while the natural areas are usually of public property and therefore better protected.

The abandonment of the agricultural activities is a process common to all the EU member States, even if at different levels of intensity. There is not a consensus about the long term consequences of such process upon the ecosystem services; in any case, the process is in full development and there is not a sign of its reversal in the next future. Environmental (e.g. soil fertility, terrain morphology, climatology) and socio-economic factors (e.g. market incentives, demographic structure of the workforce, accessibility from/to major towns) are claimed to cause and sustain such process [Pointereau et al., 2008].

The abandonment of cropping practices in the agricultural areas can impact on land cover (as well as on land use) along two quite different paths:
- A process of re-naturization;

- A process of artificialization.

Which one of the above processes actually starts and consolidates is the result of the dynamical properties of the territory (with reference both to the geophysical features and to the socioeconomical dimensions).

The two processes differ at least from the following points of view:

- Time scale: re-naturization spans over 10+ years; artificialization quickly develops where an initial seed consolidates;

- Irreversibility: in practical terms, artificialization is irreversible; re-naturization can be halted or steered towards alternative states.

In the following, relevant land cover classes are drawn from the legend proposed by [Aleksandrowicz et al., 2014] that shows eleven classes and is similar to Anderson's level-I legend [Anderson et al., 1976]; the equivalent CORINE land cover classes (EEA, 2007) are also associated.

The process of re-naturization initially moves land cover from class "Agricultural areas" (in terms of CORINE land cover classes: class 2 - Agricultural areas; here the subclasses 2.1.1 - Non-irrigated arable land and 2.4.1 - Annual crops associated with permanent crops are of interest) to "Grassland" and then to "Sparse woody vegetation" (class 3.2 - Shrubs and/or herbaceous vegetation association); after some years, such classes evolve to "Forest / woodland / trees" (class 3.1 - Forest), at least partially.

For sake of completeness, it should be mentioned that class "Bare ground" (class 3.3 - Open spaces with little or no vegetation) can result from re-naturization in some cases. As it will be shown later, such cases are not practically relevant, as far as discrimination of the abandoned land is of interest.

The process of artificialization can be planned or spontaneous. If planned, the class "Agricultural areas" develops directly and rather quickly into class "Urban / artificial" (class 1 - Artificial surfaces, whose subclasses 1.3.3 - Construction sites and 1.1.2 - Discontinuous urban fabric are here of specific interest); such development usually affects areas of medium-to-large size.

If the process is spontaneous, the transformation follows a different trajectory from class 
"Agricultural areas" to class "Urban / artificial"; such trajectory comprises class "Grassland" at least as an intermediate step, on a time interval typically of one year or more. Moreover, the transformation of the affected areas from the intermediate class to the final one is not massive; on the contrary, it shows a cascade-like pattern where the modification of a small parcel induces other surrounding parcels to change land cover, with an evident multiplicative and autocorrelated effect. This latter scenario implies the presence of urban sprawl as above defined; the consequences of land taking are obviously not dealt with from a global point of view and the environmental risks are higher than in the scenario of a planned artificialization.

\section{Monitoring the urban sprawl}

The aim is to define a monitoring approach, in order not to allow urban sprawl to establish or to consolidate. This requires to address what has to be effectively monitored and how this would be feasible. In the following, such issues will be dealt in detail, in terms of change detection and of RS support to it.

In the above, the possible transformation of the cropland has been related to some environmental and socio-economic factors inducing land cover changes. Such factors can be exploited to make a stratification of the territory, i.e. to outline the areas potentially impacted by the urban sprawl. This stratification takes also into account the planning decisions released by the public authorities. Later, the areas pinpointed by such stratification will be updated on the basis of the possible evolutions of the said factors and planning decisions.

Using the stratified territory as domain of observation, the monitoring approach could rely upon the detection of only the changes from class "Agricultural areas" to class "Urban / articial" on a per-pixel- or, better, on an OBIA- basis.

As a matter of fact, the spectral separation between such two classes is quite wide; moreover, the cascade-like pattern of diffusion could be already evident; therefore the changes are usually easily marked. However, this implies that the urban sprawl process has been already started; the restoration of the previous, non-artificialized cover may prove to be difficult, when the inevitably lengthy administrative and legal procedures have to conflict with the consolidation and expansion of the changes. Therefore, it is of interest to detect an earlier stage, in advance of the actual start of the urban sprawl.
To such purpose, it should be noted that the artificialization of the areas mostly follows the abandonment of the cropping practices and, at least in some cases, also the instauration of the first stages of re- naturization. From this point of view, the change to be detected is from class "Agricultural areas" to class "Grassland", i.e. the one preceding class "Urban / artificial" according to the change trajectory previously suggested. In this case, the spectral distance may prove to be less evident; in the following, some ways to cope with this problem are mentioned.

With this approach, the state of the vegetated land cover and its spatiotemporal trajectories are seen as reliable precursors of land cover changes (and also of related land use changes). This effective information source can be exploited in order to pinpoint the areas potentially prone to land take processes; therefore, sustainable land planning and management can rely on suitable and timely decisions.

The above approach can be seen as a specialization of already adopted change detection methodologies. A review of such methodologies is provided by [Coppin et al., 2004]; object-based change detection techniques are commented in (Hussain et al., 2013). When using HR/VHR images, an operational methodology is suggested in (Aleksandrowicz et al.,, 2014), where the need of algorithms able to automate the change detection is also pinpointed. For detecting urban sprawl precursors, such algorithms have to rely both on production of vegetation indices and on the assessment of the phenological trajectories of the areas of interest.

The vegetated areas show spectral signatures that are very similar; therefore, the different covers cannot generally be discriminated on the basis of spectral data only. However, the maximum level of that similarity is found when the vegetated covers show the same phenological stage. Such stages occur at different dates for different crops during the annual cycle; therefore, multitemporal images can highlight different crops by a proper selection of dates (Gizzi et al., 1980). The relevant dates are provided by phenological surveys (Schwartz, 2013); such surveys often exploit RS data.

The pixels of a multitemporal image referring to the same crop describe a specific family of trajectories in the space of spectral co-ordinates (with the time acting as the positional parameter along the trajectory). This is specifically evident when the spectral co-ordinates are expressed 
in terms of brightness, greenness and yellowness, as in the Tasseled Cap transformation suggested by (Kauth and Thomas, 1976), mathematically equivalent to the first three components of a PCA transformation of the image data set.

Such trajectories can vary from a year to another one, according to the variability of the phenological calendar induced by the phytoclimatology. However, the positioning of the trajectories of a given crop relatively to another one is quite constant and allows the crop discrimination inside the same year, what is here of interest. The trajectories are more evident if the original spectral data are replaced by some suitable functions, more correlated to biophysical parameters of the crops. Among such functions, NDVI (Normalized Difference Vegetation Index) is defined as:

$$
\mathrm{NDVI}=(\mathrm{NIR}-\mathrm{VIS}) /(\mathrm{NIR}+\mathrm{VIS})
$$

where VIS and NIR are the radiation measured by the satellite sensor in the band respectively of visible and of near infrared.

NDVI is widely adopted and has been the basis for many other similar indices, a list of whom is provided by [Nouri et al., 2014]. NDVI assumes values in the interval from -1.0 to +1.0 : a yearly cropped area in its phenological peak shows NDVI values ranging from 0.6 to 0.9 ; lower NDVI values (from 0.2 to 0.5 ) can be found for grassland (as for re-naturized areas). For bare ground, NDVI show extremely low values (less than 0.1 ), whose annual variability is about nil; accordingly, bare ground is easily discriminated from vegetated covers. On such basis, the appearance of bare ground as possible outcome of the re-naturization process, as previously mentioned, doesn't interfere with the mapping of the abandoned land.

The time trajectory of NDVI is correlated with the values of greenness, as suggested by (Coppin and Bauer, 1994). Therefore, NDVI is here seen as the projection of the n-dimensional trajectory in the spectral space to the 1-dimensional greenness axis in the Tasseled Cap space. The yearly oscillation of the point representing a single pixel on the greenness axis is controlled by the phenological calendar, providing the reference dates for the maximum and the minimum of such oscillation. The yearly trajectory of NDVI for the main crop canopies can effectively be surveyed with a spatial resolution of 30 meters and a return time of 4 days (Pan et al., 2015).

Relying on such experiences, it can be assumed that better results can be expected from HR and VHR satellites and, moreover, when cropped land are being discriminated from abandoned land in a full spectral space, instead of exploiting a 1-dimensional only indices as NDVI and similar ones. However, the process of extracting the principal components (as for the Tasseled Cap transformation) from a large set of high-resolution pixels has to be still completely evaluated (anyway, a useful impact on the noise reduction can be safely expected).

\section{Conclusion}

Urban sprawl is a process whose outcome is the destruction of agricultural land and its unplanned transformation into built areas. RS imagery has been exploited to analyze this process and to understand its development in time and space. Methodologies comprising inter alia data transformations, spectral indices, phenological calendars have supported the ex-post inventory and mapping of land cover changes.

The availability of HR and VHR data allow a novel ex-ante approach to the sustainable land management, based on the early detection of suitable precursors of urban sprawl. Such precursors are the (mainly reversible) land cover changes preceding the actual onset of the (practically irreversible) urban sprawl. Instead of mapping the irreversible outcome of the urban sprawl, the already proved methodologies are used in order to:

- Locate the areas whose the risk of urban sprawl is higher;

- Focus the monitoring efforts upon such areas, in order to globally detect the precursors;

- Act locally, before appearance/consolidation of urban sprawl.

The huge amount of HR and VHR data to be routinely processed for monitoring the areas of interest requires the availability of reliable tools for the automation of the workflow. Relevant algorithms should to be based on OBIA techniques, preferably to per-pixel approaches, in order not to leave out non-spectral information carried by satellite imagery.

When using HR and VHR data, a point surely requiring some more consideration is the building of the legend describing the land cover classes. Applying OBIA in a strongly automated workflow, a greater integration of the semantic definition and of the image separability of the land cover classes appears to be necessary. The hierarchical legends should include on their nodes classes differentiated by both meaning and appearance, at least 
in a balanced way. Anyway, this would entail revising some administrative rules, not only some technical ones. Should this improvements be feasible, change trajectories could be expressed as a more precise succession of classes; therefore, more powerful precursors will be available.

Corresponding author:

Corrado Iannucci

IPTSAT Srl via Sallustiana 23, 00187 Rome Italy

E-mail: corrado.iannucci@gmail.com

\section{References}

[1] Aleksandrowicz, S., Turlej, K., Lewiński, S. and Bochenek, Z. (2014) "Change detection algorithm for the production of land cover change maps over the European Union countries", Remote Sensing, Vol. 6, pp. 5976-5994. ISSN 2072-4292.

[2] Anderson, J. R., Hardy, E. E., Roach, J. T. and Witmer, R. E. (1976) "A Land Use and Land Cover Classification System for Use with Remote Sensor Data", Geological Survey Professional Paper 964. Washington DC: US Government Printing Office.

[3] Bhatta, B. (2010) "Analysis of Urban Growth and Sprawl from Remote Sensing Data". Berlin DE: Springer Verlag. ISBN 978-3-642-05299-6.

[4] Blaschke, T. (2010) "Object based image analysis for remote sensing", ISPRS Journal of Photogrammetry and Remote Sensing. Vol. 65, pp. 2-16. ISSN 0924-2716.

[5] Coppin, P. R. and Bauer, M. E. (1994) "Processing of multitemporal Landsat TM imagery to optimize extraction of forest cover", IEEE Transactions on Geoscience and Remote Sensing. Vol. 32, No. 4, pp. 918-927. ISSN, 0196-2892.

[6] Coppin, P., Jonckheere, I. ., Nackaerts, K., Muys, B. and Lambin, E. "Digital change detection methods in ecosystem monitoring: a review", Int. J. Remote Sensing. Vol. 25, No. 9, pp. 1565-1596. ISSN 2072-4292.

[7] EC (2011) "Roadmap to a Resource Efficient Europe". Communication from the Commission to the European Parliament, the Council, the European Economic and Social Committee and the Committee of the Regions. COM(2011) 571 Final. Brussels BE: European Commission.

[8] EEA (2006) "Urban Sprawl in Europe. The Ignored Challenge". EEA Report No. 10/2006. Luxembourg LU: Office for Official Publications of the European Communities.

[9] EEA (2007) "CLC2006 Technical Guidelines". EEA Report No 17/2007. Luxembourg LU: Office for Official Publications of the European Communities.

[10] EEA (2013) "Natural Resources and Human Well-being in a Green Economy"- Environmental Indicator Report 2013. Copenhagen DK: European Environment Agency.

[11] EEA (2015) "The European Environment State and Outlook 2015", Synthesis Report. Copenhagen DK: European Environment Agency.

[12] Gizzi, S., Giovacchini, A. and Iannucci, C. (1980) "Remote sensing and agriculture: a national program in Italy. Some technical aspects". In Proc. $14^{\text {th }}$ Int. Symposium on the Remote Sensing of Environment, S. José, Costa Rica. Ann Arbor MI: Environmental Research Institute of Michigan, Vol. 2, pp. 763-772.

[13] Hussain, M., Chen, D., Cheng, A., Wei, H. and Stanley, D. (2013) "Change detection from remotely sensed images: From pixel-based to object-based approaches", ISPRS Journal of Photogrammetry and Remote Sensing, vol. 80, pp. 91-106. ISSN 0924-2716.

[14] INSPIRE (2007) Directive 2007/2/EC of the European Parliament and of the Council of $14^{\text {th }}$ March 2007 establishing an Infrastructure for Spatial Information in the European Community (INSPIRE), Official Journal of the European Union, Vol. L 108, pp. 1-14. ISSN 1977-0677. 
[15] INSPIRE LC (2013) "D2.8.II.2 INSPIRE Data Specification on Land Cover - Technical Guidelines", [Online] Available: http://inspire.ec.europa.eu/documents/Data_Specifications/INSPIRE_ DataSpecification_LC_v3.0.pdf [Accessed June 10, 2015].

[16] INSPIRE LU (2013) "D2.8.III.4 INSPIRE Data Specification on Land Use - Technical Guidelines". [Online] Available: http://inspire.ec.europa.eu/documents/Data_Specifications/INSPIRE_ DataSpecification_LU_v3.0.pdf [Accessed June 15, 2015].

[17] Ji, W., Ma, J., Twibell, R. W. and Underhill, K. (2006) "Characterizing urban sprawl using multistage remote sensing images and landscape metrics", Computers, Environment and Urban Systems, Vol. 30, No. 6, pp. 861-879. ISSN 0198-9715.

[18] Kauth, R. J. and Thomas, G. S.(1976) "The tasseled cap - A graphic description of the spectraltemporal development of agricultural crops as seen by Landsat", In Proc. Symposium on Machine Processing of Remotely Sensed Data, Laboratory for Applications of Remote Sensing. West Lafayette IN: Purdue University.

[19] Nouri, H., Beecham, S., Anderson, S. and Nagler, P. (2014) "High spatial resolution WorldView-2 imagery for mapping NDVI and its relationship to temporal urban landscape evapotranspiration factors", Remote Sensing, Vol. 6, pp. 580-602. ISSN 2072-4292.

[20] Pan, Z., Huang, J., Zhou, Q., Wang, L., Cheng, Y., Zhang, H., Blackburn, G. A., Yan, J. and Liu, J. (2015) "Mapping crop phenology using NDVI time-series derived from HJ-1A/B data", International Journal of Applied Earth Observation and Geoinformation, vol. 34, pp. 188-197. ISSN 0303-2434.

[21] Pointereau, P., Coulon, F., Girard, P., Lambotte, M., Stuczynski, T., Sánchez Ortega, V. and Del Rio, A. "Analysis of Farmland Abandonment and the Extent and Location of Agricultural Areas that are Abandoned or are in Risk to be Abandoned", IES Joint Research Centre. Luxembourg LU: Office for Official Publications of the European Communities.

[22] Schwartz, M. D. (Ed.), (2013) "Phenology: an Integrative Environmental Science". Dordrecht NL: Springer Netherlands,

[23] Skidmore, A. K., Bijker, W., Schmidt, K. and Kumar, L. (1997) "Use of remote sensing and GIS for sustainable land management", ITC Journal. Vol.3/4, pp. 302-315. ISSN 2405-9595.

[24] Turner, S. (Ed.) (2002) Proceedings of the Technical Workshop on Indicators for Soil Sealing, $26^{\text {th }}$ to $27^{\text {th }}$ March 2001. Technical Report No. 80. Copenhagen DK: European Environmental Agency.

[25] UNDESA (2012) "World Urbanization Prospects", the 2011 Revision. New York, NY: United Nations, Department of Economic and Social Affairs, Population Division. 